\title{
Age determination of humpback whales Megaptera novaeangliae through blubber fatty acid compositions of biopsy samples
}

\author{
David P. Herman ${ }^{1, *}$, Gina M. Ylitalo ${ }^{1}$, Jooke Robbins ${ }^{2}$, Janice M. Straley ${ }^{3}$, \\ Christine M. Gabriele ${ }^{4}$, Phillip J. Clapham ${ }^{5}$, Richard H. Boyer ${ }^{1}$, Karen L. Tilbury ${ }^{1}$, \\ Ronald W. Pearce ${ }^{1}$, Margaret M. Krahn ${ }^{1}$ \\ ${ }^{1}$ NOAA Fisheries, Northwest Fisheries Science Center, 2725 Montlake Boulevard East, Seattle, Washington 98112, USA \\ ${ }^{2}$ Provincetown Center for Coastal Studies, 5 Holway Avenue, Provincetown, Massachusetts 02657, USA \\ ${ }^{3}$ University of Alaska Southeast, 1332 Seward Ave., Sitka, Alaska 99835, USA \\ ${ }^{4}$ Glacier Bay National Park and Preserve, PO Box 140, Gustavus, Alaska 99826, USA \\ ${ }^{5}$ National Marine Mammal Lab, Alaska Fisheries Science Center, 7600 Sandpoint Way N.E., Seattle, Washington 98115, USA
}

\begin{abstract}
The ability to determine the age of individual humpback whales Megaptera novaeangliae and estimate population age distributions is fundamental to assessments of status and long-term viability. Existing methods of ageing large whales rely either on limited longitudinal sighting studies of individual whales from their year of birth, or on post-mortem procedures to extract tissues suitable for determining age. Here we describe a potential method for ageing live free-ranging humpback whales using low-impact biopsy sampling techniques. Shallow outer-blubber samples were obtained from known-age whales from 2 distinct populations (North Atlantic, Gulf of Maine, $\mathrm{n}=39$; North Pacific, Southeast Alaska, $n=31$ ), and analyzed for their fatty acid (FA) compositions. Multilinear FAage models were derived for these known-age whales, and serve as the basis from which the age of unknown-age whales can be estimated. Four FA-age models were developed; one for each humpback population analyzed separately, and an additional 2 by combining both populations into a single dataset and deriving models based on 'exact' and 'exact' plus 'minimum' known-age whales independently. Each of these empirical models was based on a linear combination of 2 FA ratios rather than individual FA compositions, and shown to be largely independent of sex, diet and nutritional status. Although the precision $(\sigma)$ of these models was somewhat variable (ranging between 3.1 and $5.3 \mathrm{yr}$ for the specific populations modeled), the results suggest that it may be possible to estimate the age of individual humpback whales from any population with better than decadal resolution using this approach.
\end{abstract}

KEY WORDS: Humpback whale $\cdot$ Megaptera novaeangliae $\cdot$ Ageing $\cdot$ Blubber $\cdot$ Biopsy sampling Fatty acids $\cdot$ Northwest Atlantic $\cdot$ North Pacific

Resale or republication not permitted without written consent of the publisher

\section{INTRODUCTION}

Knowledge about the age of an individual animal within a population as well as the age structure of the entire population to which it belongs are both important elements for studies on cetacean population dynamics, behavior, feeding ecology and health assessment. A number of methods have been developed to estimate the age of individual cetaceans using samples obtained during capture operations or necropsies, with varying degrees of success. Counting growth layer groups (GLGs) in dentine is a frequently used method to age odontocetes (Hohn et al. 1989, Ferrero \& Walker 1999); however age estimations derived from this method may be biased depending upon tooth preparation (staining vs. non-staining) (Hohn \& Fernandez 1999). The age of mysticetes has most commonly been determined by counting ear plug GLGs, although 
some species, such as bowhead whales, have unreadable laminae. For species with readable laminae, determining the rate of GLG deposition has been problematic (Bannister et al. 2000), in part due to juveniles' irregular GLG formation, thought to be due to their irregular nutritional and migratory habits (Lockyer 1972). Examining growth layers in baleen has also historically been used to estimate the age of individuals; however this method is only useful for ageing younger whales due to the confounding effects of baleen erosion and increasing age (Ichihara 1966). A more recent method using aspartic acid racemization of the eye lens has been employed to estimate the ages of minke whales Balaenoptera acutorostrata and bowhead whales Balaena mysticetus (George et al. 1999, Olsen \& Sunde 2002), although the results typically have wide confidence intervals.

Technological advances have allowed for the development of new methods to estimate the age of living cetaceans using relatively benign sampling procedures such as biopsy sampling. This technique (Winn et al. 1973, Lambertsen 1987) is already widely used to obtain tissues for genetics and other research on freeranging whales, and is thought to have no adverse effects on the whales (Brown et al. 1991, Weinrich et al. 1992, Clapham \& Mattila 1993, Gauthier \& Sears 1999). For example, using tissues obtained from free-ranging humpback whales Megaptera novaeangliae and bottlenose dolphins Tursiops truncatus from well-studied populations, techniques are currently being developed to assign individual whales to general age classes (as well as to an estimated age), by examining the length of short, repeated sequences of DNA (telomeres) (Dennis 2006). Photo-identification studies offer valuable life-history data on populations of living whales that have been repeatedly sighted over time, but here the exact age is known only for animals that have been identified and photographed since the year of their birth. Age data obtained from longitudinal sighting studies can help 'ground truth' the results of newer cetacean ageing techniques. Using a similar groundtruthing method, Herman et al. (2008) described a new method that predicts the numerical ages of eastern North Pacific killer whales Orcinus orca using a simple, multilinear model derived from the combination of 2 specific fatty acid (FA) ratios measured in the outer layer of blubber. Prior to that study, all marine mammal FA-Age relationships noted in the literature were either essentially qualitative in nature (Møller 1999), or in some rare instances allowed approximate ages to be estimated for juveniles. For example, very short-chain fatty acids (i.e. isovaleric acid) present in the outer thorax blubber tissues of several cetacean species were shown to increase with body length, and generally increased with known age in the specific case of juve- nile and young adult male harbor porpoises (Koopman et al. 1996, 2003). In the future, novel ageing techniques such as these may provide age data for live cetaceans from other, less well-studied populations.

Humpback whale are migratory baleen whales that feed at mid- to high-latitudes, whilst fasting in lowlatitude waters during their winter breeding season (Baraff et al. 1991, Dawbin 1966). Individuals in this species can be differentiated by their natural markings, particularly the shape and ventral pigmentation pattern of the flukes (Katona et al. 1979). Photo-identification research has been carried out in a small number of humpback whale populations since the 1970s, and the sightings and demographic data accumulated on individuals have been the basis of numerous studies of humpback whale biology and population dynamics (Hammond et al. 1990, Straley et al. 2009). In these long-term studies, some individuals have been sighted over intervals of up to $37 \mathrm{yr}$; however, long-term photoidentification research is costly to maintain, and is not feasible for all populations. Even in well-studied populations, age data are not available for all individuals, and the span of research has yet to match the possible longevity of this species.

In the current study, tissue samples from distinct populations of known-age humpback whales were analyzed for outer-blubber FA compositions. Populations studied came from the western North Atlantic (Gulf of Maine and West Indies), and the North Pacific (Southeast Alaska and Hawaii). Four empirical FA-age multilinear models were then derived, and each will be shown to be sufficiently robust in several important respects to be quantitatively useful. Most importantly, these preliminary results suggest that developing empirical models from the blubber FA compositions of humpback whales can provide a relatively benign, non-lethal method from which the numerical ages of unknown-age whales can be estimated, similar to that previously demonstrated for eastern North Pacific killer whales (Herman et al. 2008). Because the FA-age relationships described herein for the humpback whale are entirely empirical in nature, the underlying biochemical mechanisms responsible for the apparent relationships between specific FAs (or FA ratios) with known age remain unknown at present; they are therefore beyond the scope of this study.

\section{MATERIALS AND METHODS}

Humpback whales sampled. Blubber biopsy samples ( $\mathrm{n}=67$ ) as well as a small number of blubber necropsy samples $(n=3)$ were collected from humpback whales of known age (exact or minimum) from both the western North Atlantic and the eastern and central North 
Pacific oceans. These samples represent a small subset of known-age animals from among a relatively large number of blubber biopsy samples that have been collected from each of these 2 populations between the summer of 2001 and fall of 2007; biopsy samples were collected in support of genetic and contaminant exposure studies conducted at the Provincetown Center for Coastal Studies, and for the Structure of Populations, Levels of Abundance, and Status of Humpbacks
(SPLASH) projects respectively. The locations where each of these samples was acquired is shown in Fig. 1; 39 samples were collected from the North Atlantic, and 31 collected from the North Pacific. Details of these sampling efforts are provided below, and key sampling and demographic information associated with each sample is shown in Table 1.

Samples collected from the western North Atlantic were from members of a distinct population whose
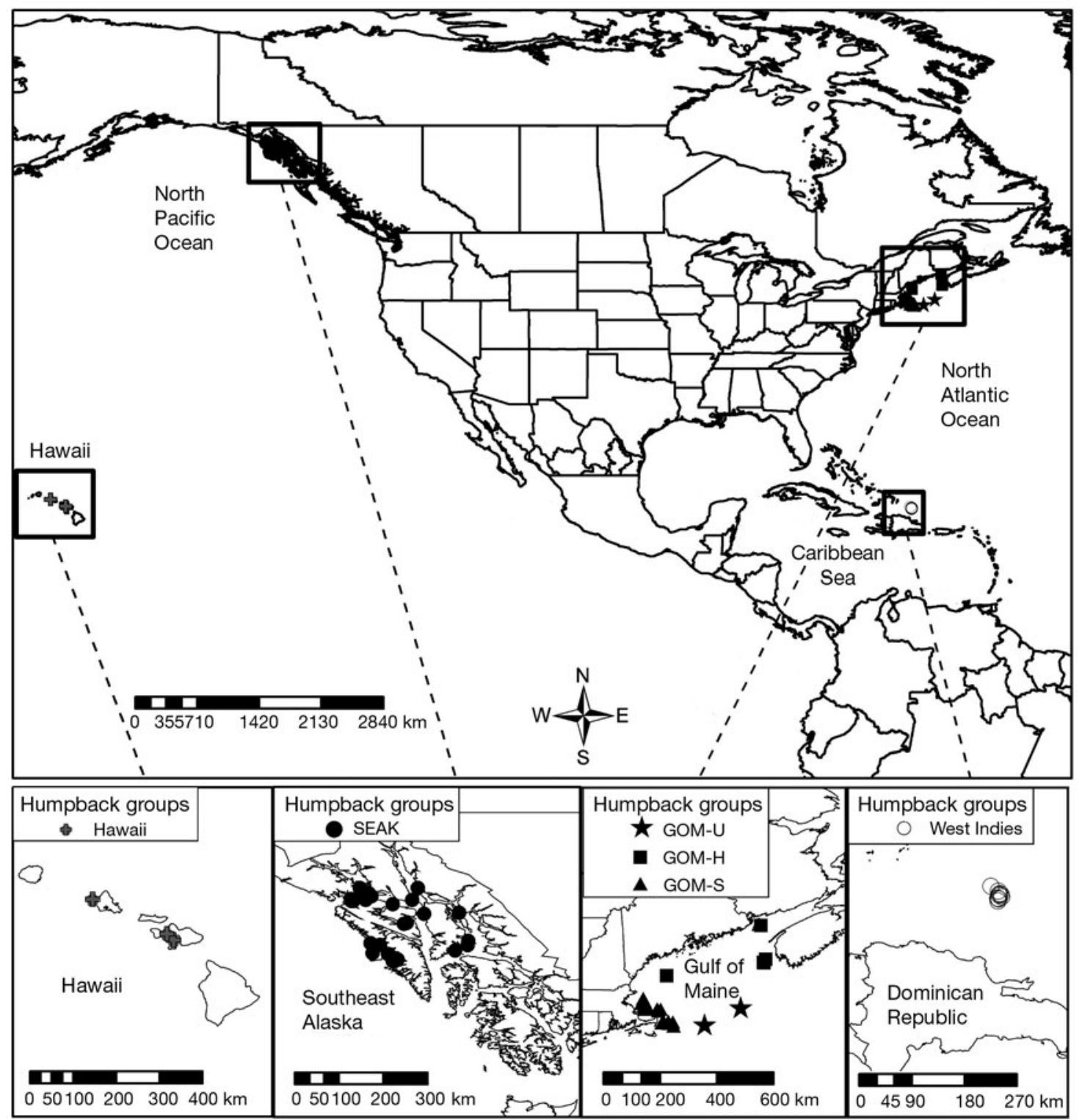

Fig. 1. Sampling locations within the western North Atlantic and eastern North Pacific oceans for the 70 known-age humpback whale blubber biopsy and necropsy samples collected and analyzed for fatty acids in this study. Samples from the Gulf of Maine (GOM) population were collected from whales on both their feeding grounds within the Gulf and on their winter mating grounds in the West Indies. Individuals identified as GOM-U, GOM-H, and GOM-S represent groupings of whales observed to have distinct location-dependent prey specializations. Abbreviations: $\mathrm{H}=$ presumed herring preference, $\mathrm{S}=$ presumed sandlance preference; $U$ = unknown prey preference. Samples from the Southeast Alaska (SEAK) population were also collected from whales on both their feeding grounds in primarily the interior waters of Southeast Alaska and on their winter mating grounds near Hawaii 
Table 1. Megaptera novaeangliae. Specimen ID no., sex, collection date (mo.d.yr), location, and known age (minimum, MKA/exact, EKA) for humpback whale biopsy samples analyzed for fatty acids (FA) and used to develop region and speciesspecific FA-age models

\begin{tabular}{|c|c|c|c|c|c|c|c|}
\hline $\begin{array}{l}\text { Sample } \\
\text { no. }\end{array}$ & Specimen ID no. & Sex & $\begin{array}{l}\text { Collection } \\
\text { date }\end{array}$ & Location & $\begin{array}{l}\text { Age (yr) } \\
\text { (MKA) }\end{array}$ & $\begin{array}{l}\text { Age }(\mathrm{yr})^{\mathrm{a}} \\
\text { (EKA) }\end{array}$ & Excluded $^{b}$ \\
\hline \multicolumn{8}{|c|}{ Gulf of Maine population-on both feeding \& breeding (non-feeding) grounds } \\
\hline 1 & CCS2004-008 & M & 5.6 .2004 & Gulf of Maine - Southwest & & 0.22 & $\delta, \phi$ \\
\hline 2 & CCS2004-025 & M & 6.11 .2004 & Gulf of Maine - East & & 0.32 & $\varepsilon, \phi$ \\
\hline 3 & BIO-1111 & M & 2.19 .2005 & West Indies & & 1.01 & \\
\hline 4 & CCS2005-001 & $\mathrm{F}$ & 5.5 .2005 & Gulf of Maine - Southwest & & 1.22 & \\
\hline 5 & CCS2004-023 aka CCS2004-078c & $\mathrm{M}$ & 6.11 .2004 & Gulf of Maine - East & 1.32 & & $\varepsilon$ \\
\hline 6 & CCS2004-078 aka CCS2004-023' & $\mathrm{M}$ & 8.26 .2004 & Gulf of Maine - East & 1.53 & & $\varepsilon$ \\
\hline 7 & CCS2004-032 & $\mathrm{F}$ & 7.26 .2004 & Gulf of Maine - North & & 2.44 & \\
\hline 8 & CCS2004-033 & $\mathrm{F}$ & 7.26 .2004 & Gulf of Maine - North & & 2.44 & \\
\hline 9 & CCS2004-107 & M & 9.12 .2004 & Gulf of Maine - Southwest & & 2.58 & $\varepsilon$ \\
\hline 10 & BIO-2023 & M & 3.8.2005 & West Indies & & 4.06 & \\
\hline 11 & CCS2005-072 & M & 8.25 .2005 & Gulf of Maine - North & & 4.52 & \\
\hline 12 & CCS2007-048 & $\mathrm{F}$ & 7.13 .2007 & Gulf of Maine - Southwest & & 6.41 & \\
\hline 13 & BIO-194 aka CCS2007-028c & M & 2.8 .2004 & West Indies & & 6.98 & \\
\hline 14 & CCS05WR0508 & $\mathrm{F}$ & 9.4.2005 & Gulf of Maine - Southwest & & 8.55 & \\
\hline 15 & CCS2007-108 & M & 11.10 .2007 & Gulf of Maine - Southwest & & 8.73 & \\
\hline 16 & BIO-604 & M & 12.02 .2005 & West Indies & 8.99 & & \\
\hline 17 & CCS2005-006 & $\mathrm{F}$ & 20.06.2005 & Gulf of Maine - Southwest & 9.34 & & \\
\hline 18 & CCS2007-009 & $\mathrm{F}$ & 24.05 .2007 & Gulf of Maine - Southwest & & 10.27 & \\
\hline 19 & CCS2007-028 aka BIO-194 & M & 07.06 .2007 & Gulf of Maine - Southwest & 10.31 & & \\
\hline 20 & CCS2007-105 & M & 10.11 .2007 & Gulf of Maine - Southwest & & 10.73 & \\
\hline 21 & CCS2007-051 & M & 21.07 .2007 & Gulf of Maine - North & & 13.43 & \\
\hline 22 & BIO-704 aka BIO-792 & $\mathrm{F}$ & 14.02 .2005 & West Indies & 17.00 & & \\
\hline 23 & BIO-792 aka BIO-704 & $\mathrm{F}$ & 15.02.2005 & West Indies & 17.00 & & \\
\hline 24 & BIO-1641 & $\mathrm{F}$ & 04.03 .2005 & West Indies & 17.01 & & \\
\hline 25 & BIO-452 aka CCS2007-027 & M & 08.02 .2005 & West Indies & & 17.98 & \\
\hline 26 & BIO-928 & $\mathrm{F}$ & 17.02 .2005 & West Indies & & 19.01 & \\
\hline 27 & CCS2004-052 & $\mathrm{F}$ & 7.27 .2004 & Gulf of Maine - North & 19.45 & & \\
\hline 28 & BIO-820 & M & 2.16 .2005 & West Indies & 20.01 & & \\
\hline 29 & CCS2007-027aka BIO-452 & M & 6.7 .2007 & Gulf of Maine - Southwest & 20.31 & & \\
\hline 30 & CCS2004-117 & $\mathrm{F}$ & 10.29 .2004 & Gulf of Maine - Southwest & & 21.70 & \\
\hline 31 & CCS2006-004 & $\mathrm{F}$ & 5.8.2006 & Gulf of Maine - Southwest & 22.23 & & \\
\hline 32 & CCS06WR0603 & M & 7.9 .2006 & Gulf of Maine - Southwest & 23.39 & & \\
\hline 33 & CCS2006-037 & $\mathrm{F}$ & 8.14 .2006 & Gulf of Maine - Southwest & 24.49 & & \\
\hline 34 & CCS2007-018 & $\mathrm{F}$ & 5.24 .2007 & Gulf of Maine - Southwest & & 25.27 & \\
\hline 35 & CCS2005-011 & $\mathrm{F}$ & 6.20 .2005 & Gulf of Maine - Southwest & 25.34 & & \\
\hline 36 & CCS2004-124 & $\mathrm{F}$ & 11.10 .2004 & Gulf of Maine - Southwest & 26.74 & & \\
\hline 37 & BIO-549 & M & 2.11 .2005 & West Indies & 26.99 & & \\
\hline 38 & CCS2007-023 & M & 6.7 .2007 & Gulf of Maine - Southwest & & 30.31 & \\
\hline 39 & CCS2004-085 & $\mathrm{F}$ & 9.7.2005 & Gulf of Maine - Southwest & 30.56 & & \\
\hline \multicolumn{8}{|c|}{ Southeast Alaska population-on both feeding and breeding (non-feeding) grounds } \\
\hline 40 & UASE-TT-20050501-003 & ? & 5.1 .2005 & Southeast Alaska & & 0.29 & $\phi$ \\
\hline 41 & GBNP-MnA-2004 ${ }^{\mathrm{d}}$ & M & 8.1.2004 & Southeast Alaska & & 0.46 & $\phi$ \\
\hline 42 & OT-041110-03 - & M & 11.10 .2004 & Southeast Alaska & & 1.74 & \\
\hline 43 & UASE-OT-040708-001 & $?$ & 7.8 .2004 & Southeast Alaska & & 2.40 & \\
\hline 44 & UASE-OT-040716-003 & $?$ & 7.16 .2004 & Southeast Alaska & & 3.42 & \\
\hline 45 & OSI-006 & $?$ & 2.25 .2004 & Hawaii & & 4.03 & \\
\hline 46 & GB2008-03 & $?$ & 7.16 .2008 & Southeast Alaska & & 4.41 & \\
\hline 47 & UASE-OT-040624-006 & $?$ & 6.24 .2004 & Southeast Alaska & & 6.35 & \\
\hline 48 & GB2008-01 & M & 7.16 .2008 & Southeast Alaska & 6.41 & & \\
\hline 49 & MN020207-01 & $\mathrm{F}$ & 2.7 .2007 & Southeast Alaska & & 6.98 & \\
\hline 50 & TDI-005-05 & $?$ & 1.20 .2006 & Hawaii & & 8.93 & \\
\hline 51 & UASE-OT-040909-004 & M & 9.9.2004 & Southeast Alaska & & 9.56 & \\
\hline 52 & OT-040624-05 & $\mathrm{F}$ & 6.24 .2004 & Southeast Alaska & & 13.35 & \\
\hline 53 & UASE-HE20050620-003 & $\mathrm{F}$ & 6.20 .2005 & Southeast Alaska & & 15.35 & \\
\hline 54 & UASE-OT-040625-001 & $\mathrm{F}$ & 6.25 .2004 & Southeast Alaska & & 16.36 & \\
\hline 55 & GB2008-04 & $\mathrm{F}$ & 7.16 .2008 & Southeast Alaska & & 16.41 & \\
\hline 56 & $\mathrm{Mn}-071307^{\mathrm{d}}$ & M & 7.13 .2007 & Southeast Alaska & 16.41 & & \\
\hline 57 & TDI-06-032 & M & 1.20 .2006 & Hawaii & & 16.93 & \\
\hline
\end{tabular}


Table 1 (continued)

\begin{tabular}{|c|c|c|c|c|c|c|c|}
\hline $\begin{array}{l}\text { Sample } \\
\text { no. }\end{array}$ & Specimen ID no. & Sex & $\begin{array}{l}\text { Collection } \\
\text { date }\end{array}$ & Location & $\begin{array}{l}\text { Age }(y r)^{a} \\
(\mathrm{MKA})\end{array}$ & $\begin{array}{l}\text { Age }(y r)^{\mathrm{a}} \\
\text { (EKA) }\end{array}$ & Excluded $^{\mathrm{b}}$ \\
\hline \multicolumn{8}{|c|}{ Southeast Alaska population-on both feeding and breeding (non-feeding) grounds (continued) } \\
\hline 58 & HE-050624-01 & M & 6.24 .2005 & Southeast Alaska & & 17.35 & \\
\hline 59 & UASE-TT-20050422-001 & $\mathrm{F}$ & 4.22 .2005 & Southeast Alaska & & 19.19 & $\phi$ \\
\hline 60 & GB2008-02 & $\mathrm{F}$ & 7.16 .2008 & Southeast Alaska & & 19.41 & \\
\hline 61 & UASE-OT-040605-001 & $\mathrm{F}$ & 6.5 .2004 & Southeast Alaska & 21.31 & & \\
\hline 62 & GB2008-07 & $\mathrm{F}$ & 8.21 .2008 & Southeast Alaska & & 21.52 & \\
\hline 63 & UASE-OT-20050805-002 & $\mathrm{F}$ & 8.5.2005 & Southeast Alaska & 23.47 & & \\
\hline 64 & UASE-HE-20050620-002 & M & 6.20 .2005 & Southeast Alaska & 24.35 & & \\
\hline 65 & UAFB-OT-040810-010 & M & 8.10 .2004 & Southeast Alaska & 25.48 & & \\
\hline 66 & GB2008-06 & M & 7.29 .2008 & Southeast Alaska & & 26.45 & \\
\hline 67 & UAFB-OT-040812-001 & $\mathrm{F}$ & 8.12 .2004 & Southeast Alaska & 28.49 & & \\
\hline 68 & UASE-OT-040625-003 & $\mathrm{F}$ & 6.25 .2004 & Southeast Alaska & 30.35 & & \\
\hline 69 & GB2008-05 & M & 7.29 .2008 & Southeast Alaska & & 34.45 & \\
\hline 70 & GBNP-Mn-2001 ${ }^{\mathrm{d}}$ & $\mathrm{F}$ & 7.18 .2001 & Southeast Alaska & & 44.50 & \\
\hline \multicolumn{8}{|c|}{$\begin{array}{l}\text { a Known (minimum/exact) age of humpback whale at time of biopsy sampling. EKA whales were first identified as calves } \\
(<1 \mathrm{yr}) \text { and are therefore believed to be precise to within } \pm 1 \mathrm{yr} \text {. MKA whales were not calves when first observed and there- } \\
\text { fore assumed to be minimally } \geq 1 \mathrm{yr} \text { at first sighting }\end{array}$} \\
\hline \multicolumn{8}{|c|}{$\begin{array}{l}{ }^{b} \text { Whales that were excluded during derivation of all FA-age modeling due to: }(\delta) \leq 5 \% \text { total lipid; }(\varepsilon)>5 \% \text { phospholipid; } \\
(\phi)<1 \mathrm{yr} \text { in age }\end{array}$} \\
\hline \multicolumn{8}{|c|}{ 'Individual whales that were repeat biopsy sampled } \\
\hline \multicolumn{8}{|c|}{$\begin{array}{l}\text { dStranded whales in which the outer-blubber was obtained by necropsy. All others were obtained as shallow biopsy samples } \\
\text { from live whales }\end{array}$} \\
\hline
\end{tabular}

spring-autumn feeding habitat is the Gulf of Maine (GOM). In winter, these whales migrate to mating grounds in the West Indies. A total of 23 samples were obtained from individuals of exact known age (EKA) ranging from $<1$ to $30.3 \mathrm{yr}$ (the oldest documented age in this population). An additional 16 samples (spanning humpback whales of age 1.3 to $30.6 \mathrm{yr}$ ) were obtained from individuals whose EKA was not known, but for whom estimates of minimum known age (MKA) could be derived via documented sighting histories; 28 samples of this population were collected on their feeding grounds in the Gulf of Maine. Sampling spanned the feeding season (April through December) and targeted aggregation sites in the southwest and northeast part of the range, as these were thought to have different prey bases. The remaining 11 samples were collected in the West Indies breeding grounds, from individuals subsequently matched to the GOM population by photo-identification techniques. Breeding ground sampling was undertaken on Silver Bank (Dominican Republic) between February and March. As shown in Table 1, duplicate samples were acquired from 4 individual whales that were re-sampled over periods ranging from $1 \mathrm{~d}$ to $3.3 \mathrm{yr}(\mathrm{n}=8)$.

Humpback whale blubber samples were also collected from a central stock of North Pacific humpback whales $(\mathrm{n}=31)$. Specifically, samples were taken from individuals that feed in the inland and outer coastal waters of Southeast Alaska (SEAK) before migrating to the Hawaiian Islands in winter during the breeding season, which is a period of fasting (with only very few exceptions). A total of 28 samples were collected from whales in the spring and summer SEAK feeding grounds, and 3 samples were collected during winter in the Hawaiian Islands (but from whales known to be members of the SEAK population).

In all study areas, skin and shallow blubber samples were collected from live, free-ranging whales by biopsy sampling techniques. Samples were obtained from the lateral flank of the whale using a small $(8 \times$ $40 \mathrm{~mm}$ or $5 \times 32 \mathrm{~mm}$ ) stainless steel biopsy dart tip, fired from either a crossbow (Palsbøll et al. 1991) or a modified veterinary 'capture' rifle (Barrett-Lennard et al. 1996). Each dart tip was attached to a graphite bolt or aluminum shaft; these were fitted with a flange or 'stop' to regulate penetration of the bolt/dart, and which caused it to recoil and float after sampling. Samples were removed from the dart tip and placed on ice until they could be frozen (generally within a few hours of collection).

For the SEAK population, 3 full-depth blubber core samples were acquired from freshly dead (stranded) animals using standard necropsy sampling techniques. Blubber samples from the 3 stranded whales (GBNPMn-2001, GBNP-MnA-2004 and Mn-071307) were collected from either the dorsal or ventral side of the body near the midsection. In order to closely mimic the $7 \mathrm{~mm}$ depth of blubber (as used for FA composition biopsy 
samples), the 3 SEAK necropsy samples were processed by cutting a representative narrow slice of outer-most blubber (measured 3 to $10 \mathrm{~mm}$ from the attached epidermis), and these were analyzed by the same methods used for all biopsy blubber samples (described below).

Sample preservation and integrity. Short-term preservation of biopsy samples was achieved by storage in standard laboratory freezers (approx. $-15^{\circ} \mathrm{C}$ ). Samples requiring long-term storage were frozen and stored at $-80^{\circ} \mathrm{C}$ until ready for analysis. In an attempt to standardize sample size, frozen biopsy samples were subjected to 2 lateral cuts. Firstly the epidermis was removed by cutting the sample $3 \mathrm{~mm}$ from the inside edge of the epidermis, and then a second lateral cut was made $10 \mathrm{~mm}$ from the inside edge of the epidermis (sample length approx. $7 \mathrm{~mm}$ ). Samples containing $<5 \%$ total lipid are assumed to be non-representative as a result of excessive lipid loss during biopsy dart recovery efforts in the field (Krahn et al. 2004). Thus blubber biopsy samples having $<5 \%$ total lipid (wet weight basis) in their outer blubber layers were excluded from all models and data summary results (except where noted otherwise). As a precautionary measure, blubber samples containing $>5 \%$ phospholipids (relative to total lipid) were also excluded due to the possibility that quantities in excess of this value could have resulted from excessive leaching of lipid contained in the epidermis into the $7 \mathrm{~mm}$ blubber cores analyzed in this study. In contrast to humpback whale outer-blubber tissues [that are typically greater than 99\% triacylglycerides (TAGs)], humpback skin contains significant quantities of phospholipids; alternatively, an abnormally high total phospholipids value may reflect an animal in poor health, thus significantly altering its outer-blubber FA composition (Krahn et al. 2001). The methods used in this study to measure total lipid and lipid classes are described below.

Techniques for establishing known ages (exact and minimum). For the purpose of this article, we define 'known-age' humpback whales to be either animals of exact known age (EKA), or those whose ages are known to be greater than some minimum value (MKA). Unless specified otherwise, members of the GOM and SEAK populations include whales from both their spring/summer, and winter breeding grounds (West Indies and Hawaii respectively).

Identifying photographs were obtained for each individual at the time of sampling to provide a link to prior sighting data and year of birth (when known). Longitudinal data were obtained from photo-identification catalogs curated by the Provincetown Center for Coastal Studies, J. Straley Investigations, and the Glacier Bay National Park and Preserve, USA. EKA whales in this study are individuals first photographed as calves (in the first year of life), and were photographed and biopsied in a later year. Calves were classified in the field based on their physical size, stereotypical behaviours and close (consistent) association with an adult (its mother). Calves encountered on the feeding range were assumed to range in age from 3 to 9 mo when first observed, and typically remained dependent until at least October of their first year (Clapham \& Mayo 1987 , Baraff \& Weinrich 1993). Thus, the ages of EKA whales were simply computed as the number of intervening years between first observation and when re-encountered and biopsy sampled. In contrast, individuals that were independent when first catalogued prior to October were assumed to be at least 1 yr old, but could have been substantially older. In those cases, a MKA was calculated as the elapsed time from the year prior to the first sighting to the year of biopsy sampling. All ages were calculated in months, and assumed a 15 February birth date. At the time of this study the oldest exact age known from photo-identification was $31 \mathrm{yr}$ in the Gulf of Maine, and $34 \mathrm{yr}$ in Southeast Alaska.

Age was determined for GBNP-Mn-2001 by counting growth layer groups (GLG) in the ear plugs (Chittleborough 1959, Lockyer 1984) collected during the necropsy of this stranded whale. Independent counts of GLG in both ear plugs were made by experienced ear plug readers. The present analysis used the mean of these counts, and assumes a deposition rate of 1 GLG per year (unlike Chittleborough 1959 who assumed a deposition rate of 2 GLGs per year); this has not been definitively established for humpback whales, but is the case in other baleen whales (Lockyer 1984, Bannister et al. 2000, Best 2010).

Lipid class and fatty acid analyses. Blubber samples of humpback whales were analyzed for percent lipid classes (relative to sample wet weights) using a thinlayer chromatography/flame ionization detection (TLC/FID) method (Ylitalo et al. 2005). Five lipid classes (i.e. wax + sterol esters, TAGs, free FAs, sterols and phospholipids) were analyzed on Chromarod type S-III silica rods using a 60:10:0.02 hexane:diethyl ether:formic acid (v/v/v) solvent system, and measured with an Iatroscan MK-6s (Shell, USA); in this system, wax esters co-elute with sterol esters. Percent total lipids were calculated by adding the wet weight concentrations of the 5 separated lipid classes. The concentrations of each lipid class were also recorded as a percentage of the total lipid.

FA concentrations in blubber were determined as previously reported (Krahn et al. 2004, Herman et al. 2005), and their weight percent compositions (wt\%) were expressed in units of fatty acid methyl ester (FAME). The n-number standard nomenclature system was used for abbreviating the names of these FAs, 
where the number following the ' $\mathrm{n}$ ' symbol appearing in the abbreviation refers to the carbon position of the first double bond relative to the alkyl end of the molecule. A full list of all 83 FAs measured as part of this study (of which 3 were added as internal standards), their abbreviations, systematic and trivial names, identification of the subsets of FAMEs which were positively and tentatively identified, as well as quality assurance procedures, can all be found in Sloan et al. (2006).

Statistical analyses. All FAME concentration data were expressed on a weight percent (wt\%) composition basis by dividing the concentration of each individual FAME by the sum of all FAMEs measured in the sample. With the exception of multidimensional scaling analyses, all multivariate and univariate analyses were conducted on non-transformed wt $\%$ composition concentration data using JMP Statistical Discovery Software (JMP). Unless otherwise stated, all univariate means comparisons ( $\mathrm{p}$-values) were computed using a Student's t-test $(\alpha=0.05)$.

Humpback whales were grouped by population, and the correlations (expressed as $\mathrm{r}^{2}$ ) between known ages and FA compositions (weight percent basis) for the non-excluded GOM $(\mathrm{n}=34)$ and SEAK $(\mathrm{n}=28)$ populations were computed for each individual FA. Individual FAs exhibiting positive (negative) correlations with known ages are identified as ' $+{ }^{\prime}\left({ }^{\prime}-{ }^{\prime}\right)$ values respectively, and are sorted from those having the highest mean $r^{2}$ values for the 2 populations to those having the lowest mean $r^{2}$ values.

Multi-dimensional scaling analyses (MDS) of the fatty acid composition data were performed using the Primer-E statistical software package (Primer-E). Prior to MDS analysis, the fatty acid weight percent composition data were pre-treated by: (1) selecting the subset of FAs to be compared and re-standardizing each individual FA relative to the sum of all FAs in the subset; (2) normalizing these standardized values by expressing them as normal deviate $Z$-values, thus giving equal weight to each value independent of its absolute magnitude; (3) computing an among-sample dissimilarity matrix on these normalized values based on Euclidean distances between the variables; (4) subjecting the dissimilarity matrix to classical multi-dimensional scaling analysis. The sample-to-sample proximity values (distances) resulting from the MDS analyses were then plotted in the form of 2-dimensional perceptual maps.

Multilinear regressions of FAME-age data for the known-age humpback whales were performed using the mixed (forward \& backward) step-wise search procedure in combination with the Tobit statistical analysis routine in JMP. Initially, intermediate models were derived for all possible permutations of 2 pair of FA ratios using step-wise multilinear regression and only those equations producing linear models with $\mathrm{r}^{2}$ values greater than 0.8 were retained as a subset for further analysis. Thereafter, Tobit regression analyses were performed on each of the intermediate models in order to arrive at a single model equation that best fit the MKA and/or EKA FA-age data pairs. In Tobit analyses, MKA and EKA sample data were treated as rightcensored and un-censored data respectively. The aim of these statistical analyses was to arrive at empirical model equations (bi-variate) from which the numerical ages of unknown-age humpback whales may be predicted through biopsy sampling.

Multilinear humpback whale FA-age ratio modeling. Humpback whales having known ages $<1$ yr (calves) were excluded from all statistical analyses unless otherwise noted; this was because their FA profiles were quite different from those of individuals $>1 \mathrm{yr}$ in age, and did not exhibit the same continuous change in blubber FA composition with age as observed in older individuals. All individuals having $<5 \%$ total lipid or $>$ $5 \%$ phospholipids in their outer-blubber were also excluded as outliers in these analyses (as noted above). Blubber FA composition results for the 62 non-excluded known-age humpback whales (Table 1) were subjected to multilinear regression analyses to determine if multilinear combinations (of either individual FAs or combinations of FA ratios) could be found that would simultaneously (1) reduce the variability (scatter) among individuals about the FA-age model equation, and (2) be largely independent of sex, population, diet, and feeding status. Among all the models tested, simple linear combinations of 2 pairs of non-transformed FA ratios were found to provide the best correlation between humpback whale age and outer blubber FA composition for all whales studied (independent of the demographics and presumptive diets listed above). Models incorporating more than 2 FA ratio variables into the multilinear regression equations did not significantly reduce scatter further; therefore all multilinear regression models (including Tobit right-censored models) were limited to 2 constructed-variables (i.e. 4 FAs expressed as 2 FA ratios).

Estimation of model precision. Two indices of precision (uncertainty) were derived for each Tobit regression model derived herein. The first estimate of precision for each model $\left(\sigma_{\text {Tobit }}\right)$ was derived directly from the modeling procedure, and is a measure of the scatter of both the EKA and MKA whales about their respective regression equation lines; however censored data are given less weight than their uncensored counterparts here. These $\sigma_{\text {Tobit }}$ values were computed directly by JMP during the derivation of the Tobit regression models, and were provided as statistical summary outputs. A second estimate of model precision was derived using a bootstrapping procedure in order to obtain an independent estimate of 
how well these models may perform when applied to unknown age animals that were not part of the original modeling process. Although is not possible to use bootstrapping procedures when estimating the prediction success of regression models containing both censored and uncensored data, we have no a priori reason to believe that the blubber chemistry of the MKA (censored) animals were fundamentally different from the EKA (uncensored) whales; hence, the scatter of EKA whales about these bivariate regression equations should be a suitable estimate of model precision without including MKA data into the models. Bootstrap estimates of precision $\left(\sigma_{\mathrm{BS}}\right)$ were derived by randomly removing $30 \%$ of the EKA animals from the dataset, fitting the remaining $70 \%$ to the bivariate FA ratio model equation, and then using this new model to predict the ages of the excluded animals. The differences between the predicted age (PA) and the observed EKA were recorded, and this random selection with substitution bootstrapping procedure repeated 30 times. $\sigma_{\mathrm{BS}}$ was computed as the standard deviation of the residual differences obtained from all 30 repetitions.

\section{RESULTS}

\section{Lipid-class analyses}

With only 2 exceptions, the percentage total lipid composition (relative to wet weight) measured in the

Table 2. Megaptera novaeangliae. Correlations of individual fatty acids (FAs) with age for Gulf of Maine (n=20) and Southeast Alaska $(n=20)$ humpback whale populations. Correlations $\left(\mathrm{r}^{2}\right)$ were computed for exact-aged animals only; animals $<1 \mathrm{yr}$ of age, $<5 \%$ total lipid, or $>5 \%$ phospholipid were excluded as outliers in this analysis. FA concentrations were expressed in units of $\mathrm{wt} \%$ composition. FAs are sorted in the order of highest to lowest summed $\mathrm{r}^{2}$ values $\left(\Sigma \mathrm{r}^{2}=\mathrm{r}_{\mathrm{GOA}}^{2}+\mathrm{r}^{2}\right.$ SEAK $)$. FAs marked with asterisks indicated those that statistically signifcantly increase (decrease) with known age for both the GOM and SEAK populations simultaneously at probabilities $\mathrm{p}<0.10\left({ }^{*}\right), \mathrm{p}<0.05\left({ }^{* *}\right), \mathrm{p}<0.01\left({ }^{* * *}\right), \mathrm{p}<0.001\left({ }^{* * *}\right)$. $+/-$ indicate positive/negative correlations, respectively

\begin{tabular}{|c|c|c|c|c|c|c|c|c|c|}
\hline Fatty acid & \multicolumn{2}{|c|}{ Gulf of Maine } & \multicolumn{2}{|c|}{ Southeast Alaska } & Fatty acid & \multicolumn{2}{|c|}{ Gulf of Maine } & \multicolumn{2}{|c|}{ Southeast Alaskó } \\
\hline 261014-Me-C15:0 ** & 0.87 & $(+)$ & 0.24 & $(+)$ & $\mathrm{C} 16: 2 \mathrm{n} 4$ & 0.34 & $(-)$ & 0.12 & $(-)$ \\
\hline $\mathrm{C} 20: 0^{* * *}$ & 0.66 & $(+)$ & 0.44 & $(+)$ & Anteiso-C17:0 & 0.10 & $(-)$ & 0.35 & $(-)$ \\
\hline $\mathrm{C} 20: 1 \mathrm{n} 15^{* * *}$ & 0.70 & $(+)$ & 0.39 & $(+)$ & $\mathrm{C} 18: 4 \mathrm{n} 1$ & 0.33 & $(-)$ & 0.10 & $(-)$ \\
\hline $\mathrm{C} 24: 1 \mathrm{n} 9^{* * *}$ & 0.60 & $(+)$ & 0.36 & $(+)$ & C20:1n 7 & 0.01 & $(+)$ & 0.42 & $(+)$ \\
\hline $\mathrm{C} 22: 1 \mathrm{n} 9^{* * * *}$ & 0.47 & $(+)$ & 0.47 & $(+)$ & $\mathrm{C} 22: 0$ & 0.38 & $(+)$ & 0.00 & $(-)$ \\
\hline $\mathrm{C} 22: 1 \mathrm{n} 7^{* *}$ & 0.45 & $(+)$ & 0.47 & $(+)$ & Iso-C16:0 & 0.04 & $(-)$ & 0.33 & $(-)$ \\
\hline $\mathrm{C} 22: 5 \mathrm{n} 3^{* * *}$ & 0.41 & $(-)$ & 0.51 & $(-)$ & $\mathrm{C} 18: 3 \mathrm{n} 4$ & 0.29 & $(-)$ & 0.05 & $(-)$ \\
\hline $\mathrm{C} 20: 1 \ln 9^{* * *}$ & 0.44 & $(+)$ & 0.42 & $(+)$ & $\mathrm{C} 18: 2 \mathrm{n} 4$ & 0.31 & $(-)$ & 0.03 & $(-)$ \\
\hline $\mathrm{C} 18: 2 \mathrm{n} 7^{* *}$ & 0.55 & $(-)$ & 0.27 & $(-)$ & $\mathrm{C} 22: 4 \mathrm{n} 6$ & 0.11 & $(+)$ & 0.21 & $(+)$ \\
\hline 4812-Me-C13:0 & 0.70 & $(+)$ & 0.12 & $(+)$ & C18:1n5 & 0.17 & $(-)$ & 0.12 & $(+)$ \\
\hline $\mathrm{C} 20: 4 \mathrm{n} 6^{* *}$ & 0.29 & $(-)$ & 0.53 & $(-)$ & C19:0 & 0.05 & $(-)$ & 0.25 & $(-)$ \\
\hline $\mathrm{C} 22: 1 \mathrm{n} 11^{* * *}$ & 0.32 & $(+)$ & 0.49 & $(+)$ & C18:3n3 & 0.00 & $(-)$ & 0.26 & $(-)$ \\
\hline $\mathrm{C} 20: 1 \mathrm{n} 11^{* *}$ & 0.27 & $(+)$ & 0.51 & $(+)$ & $\mathrm{C} 20: 3 \mathrm{n} 3$ & 0.01 & $(-)$ & 0.23 & $(-)$ \\
\hline $\mathrm{C} 16: 4 \mathrm{n} 3^{* * *}$ & 0.34 & $(-)$ & 0.41 & $(-)$ & $\mathrm{C} 16: 1 \mathrm{n} 11$ & 0.00 & $(+)$ & 0.20 & $(-)$ \\
\hline $\mathrm{C} 22: 6 \mathrm{n} 3^{* *}$ & 0.28 & $(-)$ & 0.44 & $(-)$ & $\mathrm{C} 16: 4 \mathrm{n} 1$ & 0.17 & $(+)$ & 0.03 & $(+)$ \\
\hline $\mathrm{C} 16: 0^{* *}$ & 0.26 & $(-)$ & 0.43 & $(-)$ & $\mathrm{C} 16: 3 n 4$ & 0.08 & $(+)$ & 0.11 & $(+)$ \\
\hline $\mathrm{C} 18: 0^{* *}$ & 0.21 & $(-)$ & 0.48 & $(-)$ & Iso-C15:0 & 0.02 & $(+)$ & 0.15 & $(-)$ \\
\hline $7-\mathrm{Me}-\mathrm{C} 16: 1^{* *}$ & 0.30 & $(+)$ & 0.38 & $(+)$ & $\mathrm{C} 16: 1 \mathrm{n} 7$ & 0.16 & $(-)$ & 0.00 & $(+)$ \\
\hline $\mathrm{C} 22: 2 \mathrm{n} 6$ & 0.49 & $(+)$ & 0.13 & $(+)$ & $\mathrm{C} 18: 4 \mathrm{n} 3$ & 0.06 & $(+)$ & 0.08 & $(-)$ \\
\hline $\mathrm{C} 16: 2 \mathrm{n} 6^{* *}$ & 0.30 & $(+)$ & 0.31 & $(+)$ & $\mathrm{C} 18: 2 \mathrm{n} 6$ & 0.01 & $(+)$ & 0.12 & $(-)$ \\
\hline C20:1n5 & 0.51 & $(+)$ & 0.10 & $(+)$ & Anteiso-C15:0 & 0.03 & $(+)$ & 0.10 & $(-)$ \\
\hline $\mathrm{C} 20: 3 \mathrm{n} 6{ }^{* *}$ & 0.22 & $(-)$ & 0.37 & $(-)$ & $\mathrm{C} 20: 2 \mathrm{n} 6$ & 0.00 & $(+)$ & 0.12 & $(-)$ \\
\hline $\mathrm{C} 20: 5 \mathrm{n} 3$ & 0.12 & $(-)$ & 0.45 & $(-)$ & $\mathrm{C} 12: 0$ & 0.02 & $(-)$ & 0.11 & $(-)$ \\
\hline C18:1n9 & 0.11 & $(-)$ & 0.45 & $(+)$ & Iso-C14:0 & 0.03 & $(+)$ & 0.09 & $(-)$ \\
\hline $\mathrm{C} 14: 1 \mathrm{n} 5^{*}$ & 0.15 & $(+)$ & 0.41 & $(+)$ & $\mathrm{C} 14: 1 \mathrm{n} 7$ & 0.03 & $(+)$ & 0.08 & $(+)$ \\
\hline $\mathrm{C} 20: 4 \mathrm{n} 3$ & 0.12 & $(-)$ & 0.43 & $(-)$ & C18:1n13 & 0.06 & $(-)$ & 0.04 & $(+)$ \\
\hline Iso-C18:0 ${ }^{*}$ & 0.17 & $(-)$ & 0.37 & $(-)$ & C16:1n5 & 0.02 & $(-)$ & 0.07 & $(-)$ \\
\hline Iso-C $17: 0^{* *}$ & 0.21 & $(-)$ & 0.33 & $(-)$ & C18:3n6 & 0.04 & $(+)$ & 0.05 & $(-)$ \\
\hline $\mathrm{C} 17: 1 \mathrm{n} 8^{* *}$ & 0.22 & $(-)$ & 0.30 & $(-)$ & C14:0 & 0.00 & $(+)$ & 0.08 & $(+)$ \\
\hline $\mathrm{C} 18: 1 \mathrm{n} 7^{*}$ & 0.31 & $(-)$ & 0.18 & $(-)$ & C14:1n9 & 0.00 & $(+)$ & 0.07 & $(-)$ \\
\hline $\mathrm{C} 22: 4 \mathrm{n} 3$ & 0.13 & $(-)$ & 0.35 & $(-)$ & C20:2n11 & 0.02 & $(+)$ & 0.05 & $(-)$ \\
\hline $\mathrm{C} 17: 0^{*}$ & 0.14 & $(-)$ & 0.33 & $(-)$ & C16:1n9 & 0.04 & $(-)$ & 0.00 & $(+)$ \\
\hline C18:1n11 & 0.13 & $(+)$ & 0.34 & $(+)$ & $\mathrm{C} 21: 5 \mathrm{n} 3$ & 0.00 & $(-)$ & 0.03 & $(-)$ \\
\hline $\mathrm{C} 15: 0^{*}$ & 0.17 & $(-)$ & 0.30 & $(-)$ & & & & & \\
\hline
\end{tabular}


outer-blubber samples of all GOM and SEAK population humpback whales (Table 1) were found to be $>5 \%$ total lipid. The lipid class composition of the lipid extracted from each of these samples was > 95\% TAGs in all but 4 samples, with most containing $100 \%$ TAGs. Among the individual humpback whales that had significant quantities of phospholipids in their blubber tissues (see Table 1), those same samples were also severely depleted in polyunsaturated fatty acids (PUFA), in particular omega-3.

\section{Blubber fatty acid compositions}

To determine how the outer-blubber FA compositions of the known-age humpback whales vary among individuals within each humpback whale population and between the 2 populations (GOM and SEAK), the

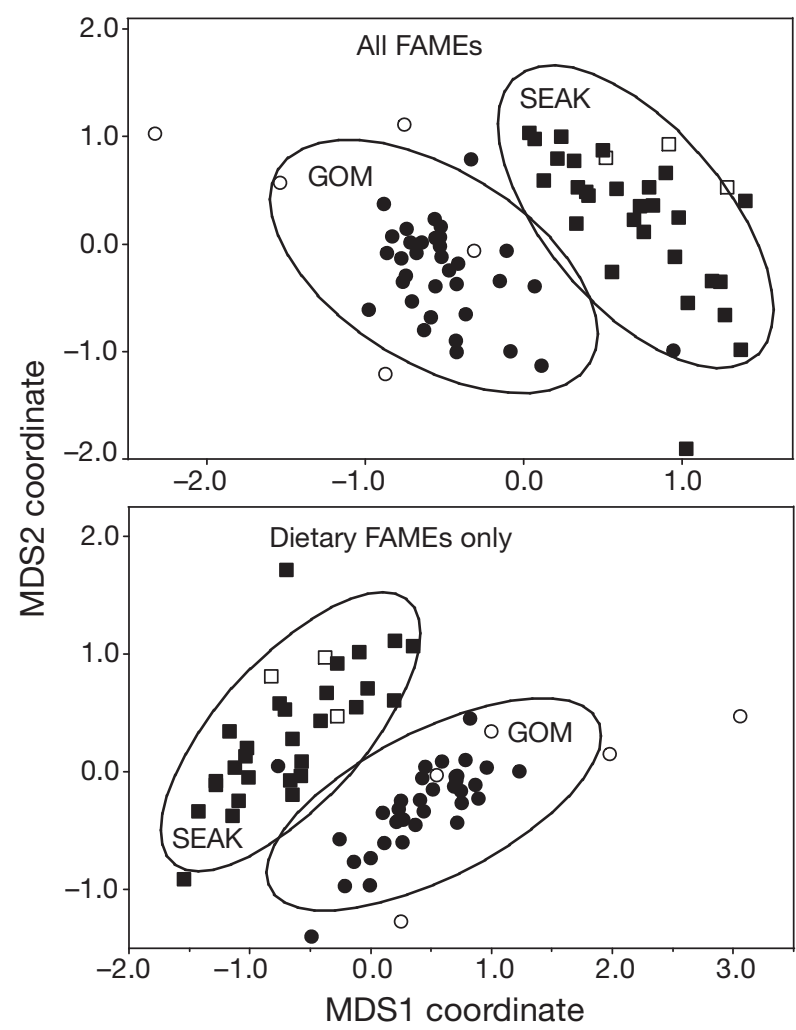

Fig. 2. Megaptera novaeangliae. Multidimensional Scaling Analysis (MDS) plots of the outer-blubber fatty acid (FA) compositions of the GOM (circles) and SEAK (squares) humpback whales collected and analyzed as part of this study. MDS plots were created from fatty acid profiles derived from all 67 quantifiable FAs (i.e. FAs both dietary and non-dietary in origin; upper panel) and from profiles representing FA believed to be predominantly dietary in origin (lower panel). The 8 samples excluded from all FA-age models (see Table 1) but included in these MDS analyses are depicted by open symbols. Ovals represent the $90 \%$ probability density functions of the 2 populations depicted. FAME: fatty acid methyl ester weight percentage composition results obtained for each of the 70 whales listed (Table 1) were subjected to multidimensional scaling analyses using the procedures outlined above. Only 67 FAs out of a total of 80 FAs were present at high enough concentrations in all samples to be accurately quantified. The abbreviated structures of these 67 quantifiable FAs are listed in Table 2. Multidimensional scaling analyses were conducted on the weight percentage composition data for all 67 quantifiable FAs measured (both dietary and non-dietary) and for the subset of FAs believed to be predominantly dietary in origin. The quantifiable subset of 16 exogenous fatty acids used in this analysis and assumed to be predominantly dietary in origin were: C18:2n6, C18:3n6, C18:3n3, C18:4n3, C20:1n9, C20:2n6, C20:3n6, C20:4n6, C20:3n3, C20:4n3, C20: 5n3, C22:1n9, C21:5n3, C22:4n6, C22:4n3, C22:6n3 (Iverson et al. 2004). The results of these 2 multivariate analyses are depicted in Fig. 2. In these plots whales were grouped by population (GOM and SEAK); differences in their respective fatty acid profiles (all FAMEs and dietary only FAMEs) were observed to be markedly different.

\section{Correlation between humpback whale age and individual fatty acids}

The classes of FAs tending to exhibit the greatest correlation to humpback whale age (Table 2) were the longer-chain monounsaturated acids (most notably the $\Delta 5-, \Delta 13-$, and $\Delta 15$ - dehydrogenase metabolites of C20:0, C22:0, and C24:0) and branched-chain FAs (most notably the multi-methyl branched-chain FAs). Although there were clearly some correlations between the known ages of humpback whales and specific individual FAs for each whale population individually, no single FA was sufficiently linearly correlated with both populations simultaneously so as to be quantitatively useful for the purpose of predicting whale age.

\section{Humpback FA-age models (GOM and SEAK combined)}

Two multilinear FA-age models were derived from the humpback whale FA and known age data collected as part of this study. Using the mixed step-wise search procedure, the first model was derived by combining the FA-age data pairs for each EKA whale from both populations into a single dataset; the MKA animals were excluded during derivation of this model. This optimum 'exact-age' model was then used to predict the ages of MKA humpbacks, and these compared 
against the MKA derived from field observations. The optimum 2 variable FA ratio equation that best fit the EKA data was:

$$
\begin{gathered}
\mathrm{AGE}(\mathrm{yr})_{\text {predicted }}=319 \times[\mathrm{C} 20: 1 \mathrm{n} 15 / \mathrm{C} 17: 1 \mathrm{n} 8] \\
+1.26 \times[\mathrm{C} 14: 1 \mathrm{n} 5 / \mathrm{C} 15: 0]-11.8
\end{gathered}
$$

and a plot showing the conformity between predicted and known ages for this model is shown in Fig. 3 (upper panel). In this plot different marker symbols were used to distinguish between the individual humpback whales from the GOM and SEAK populations; the dashed line represents the equation line predicted by Eq. (1). This optimized equation was then used to predict the ages for the non-excluded MKA whales, and these predicted ages were compared against the observed MKAs given in Fig. 3 (lower panel). Whereas animals having MKA data points appearing above the predicted equation line implicitly denote inaccuracies in the model (i.e. PA $<$ MKA), data points for MKA animals appearing below the predicted equation line are not necessarily due to inaccuracies in the model; this may instead simply reflect the very real possibility that the actual ages of these MKA whales are in fact greater than their assumed MKAs.

A second multilinear model was derived from these combined GOM and SEAK FA-age data pairs, but in this case, the multilinear regression model was derived by making use of both EKA and MKA FA-age data in contrast to the model portrayed in Fig. 3 which was based solely on the EKA FA-age data for these 2 populations. In this analysis the EKA and MKA data pairs were treated as un-censored and right-censored data respectively, and the Tobit multilinear regression method outlined above was used to find the single model equation that simultaneously best-fit data for both EKA and MKA whales. The optimum rightcensored multilinear regression model obtained via this procedure was:

$$
\begin{gathered}
\mathrm{AGE}(\mathrm{yr})_{\text {predicted }}=381 \times[\mathrm{C} 20: 1 \mathrm{n} 15 / \mathrm{C} 17: 1 \mathrm{n} 8] \\
+0.993 \times[\mathrm{C} 14: 1 \mathrm{n} 5 / \mathrm{C} 15: 0]-12.1
\end{gathered}
$$

The ages predicted by Eq. (2) for each of the individual whales from these 2 populations were compared to their EKAs or MKAs; a plot showing the agreement between predicted and known ages is provided in Fig. 4. The precision of this model, $\sigma_{\text {Tobit, }}$ was $5.25 \mathrm{yr}$, where the standard error estimate in this sigma value was $0.60 \mathrm{yr}$; the probability that $\mathrm{p}>\chi^{2}$ was $\mathrm{p}<0.001$. In contrast, the bootstrap-derived estimate of uncertainty associated with using this model to predict the age of unknown-aged whales was $\sigma_{\mathrm{BS}}=4.06 \mathrm{yr}$ where the standard error estimate in this sigma value was $0.64 \mathrm{yr}$. It is postulated that the 5 individual minimum-aged whales that have predicted ages that were significantly greater than their specified minimum ages were
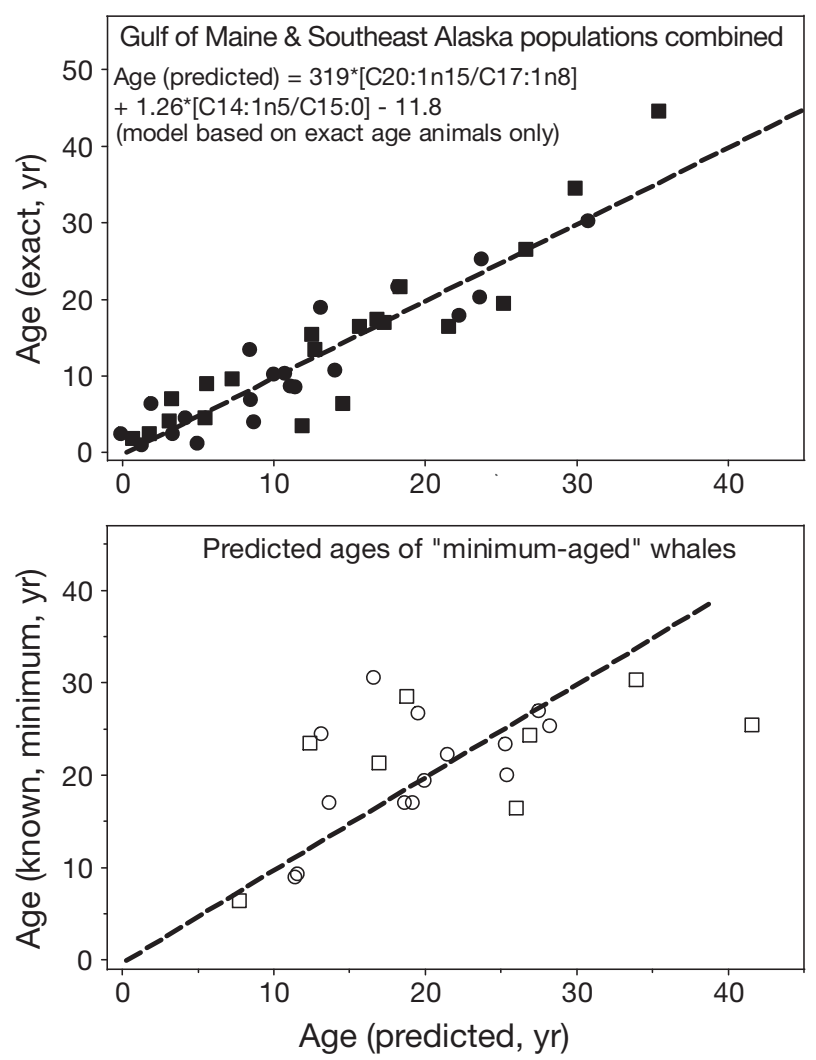

Fig. 3. Megaptera novaeangliae. Plot of exact ages against model-predicted ages (upper panel) for humpback whales from both the Gulf of Maine (circles) and Southeast Alaska (squares). Predicted ages were computed from Eq. (1) which was derived using fatty acid-age data obtained from the exact known age whales only. Ages predicted by Eq. (1) for minimum-aged whales from these 2 populations were also compared to their known minimum ages (lower panel)

in fact greater in age than the specified minimum age values and likely have true ages closer in value to those indicated by their position at the tops of the vertical arrows corresponding to these 5 whales; the tops of the vertical arrows indicate the estimated position of the $95 \%$ confidence interval of the regression equation.

\section{Humpback FA-age models (SEAK only; GOM only)}

Similar to the method described above, 2 additional bi-variate FA-age models based on both exact and minimum-aged humpback whale blubber FA ratios were derived, but in contrast to above, these rightcensored models were derived for each humpback whale population separately (hence are populationspecific). 


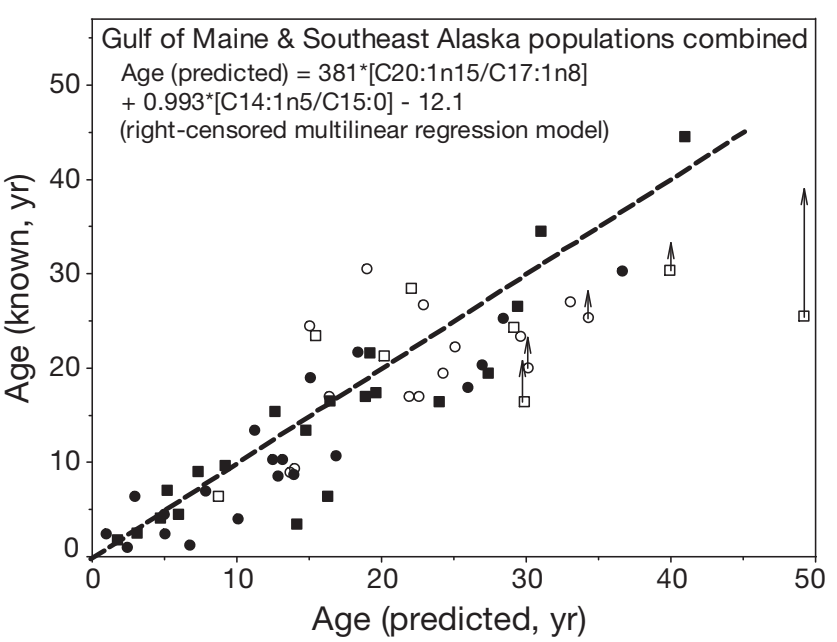

Fig. 4. Megaptera novaeangliae. Relationship between the known-ages (EKA and MKA) for the 62 non-excluded Gulf of Maine (GOM) and Southeast Alaska (SEAK) humpback whales and the ages predicted from their outer blubber fatty acid (FA) compositions using Eq. (2). The FA-age model (Eq. 2) was derived using the FA- HW(age) data from both EKA and MKA whales and employing the Tobit right-censored multilinear regression procedure described in 'Materials and methods'. The dashed line represents the point in the plot where Age(predicted) equals Age(known). Symbols: GOM (circles, $\mathrm{n}=34$ ); SEAK (squares, $\mathrm{n}=28$ ); EKA (closed, $\mathrm{n}$ =40); MKA (open, $\mathrm{n}=22$ ); MKA whales predicted by the model to be much older than their minimum values are also indicated (open symbols with vertical arrows, $\mathrm{n}=5$ ). Model uncertainties were: $\sigma_{\text {Tobit }}=5.25 \mathrm{yr}_{;} \sigma_{\mathrm{BS}}=4.06 \mathrm{yr}$

FA-age data for the 28 non-excluded known-age humpback whales from Southeast Alaska were analyzed using the Tobit right-censored procedure outlined above, and the optimum bi-variate equation that best fit these data was:

$$
\begin{gathered}
\mathrm{AGE}(\mathrm{yr})_{\text {predicted }}=74.7 \times[\mathrm{C} 20: 1 \mathrm{n} 15 / \mathrm{C} 16: 4 \mathrm{n} 3] \\
+4.26 \times[\mathrm{C} 20: 1 \mathrm{n} 7 / \mathrm{C} 17: 0]-6.97
\end{gathered}
$$

where $p>\chi^{2}(p<0.001)$. Fig. 5 shows known age plotted against ages predicted by Eq. (3) for these SEAK population humpback whales. Similar to above, 2 individual MKA whales had predicted ages that were significantly greater than their assigned MKAs, and are therefore now believed to have been underestimated by the amounts indicated (tops of vertical arrows). The uncertainties associated with this right-censored multi-linear model were $\sigma_{\text {Tobit }}=4.52(\mathrm{SE}=0.74)$ and $\sigma_{\mathrm{BS}}=4.24(\mathrm{SE}=0.68)$ yr respectively.

Similarly, a population-specific FA-age model based on both EKA and MKA humpback whale blubber FA results was constructed for the Gulf of Maine population; the optimum right-censored bi-variate FA ratio model that best fit the data for this population was:

$$
\begin{aligned}
& \mathrm{AGE}(\mathrm{yr})_{\text {predicted }}=162 \times[4,8,12 \mathrm{MeC} 13: 0 / \mathrm{C} 20: 4 \mathrm{n} 6] \\
& \quad+1.62 \times[\mathrm{C} 20: 0 / 2,6,10,14 \mathrm{MeC} 15: 0]+14.3
\end{aligned}
$$

A plot of the known ages for these individual GOM humpbacks compared against their ages predicted by Eq. (4) is shown in Fig. 6. Among this group of individuals, 4 whales had predicted ages that were substantially above their MKA; thus, leading us to now believe that the true ages of these 4 whales are in fact substantially higher than their specified MKAs. In this GOMspecific model $\mathrm{p}>\chi^{2}(\mathrm{p}<0.001)$, and the uncertainties were estimated to be $\sigma_{\text {Tobit }}=3.25(\mathrm{SE}=0.53)$ and $\sigma_{\mathrm{BS}}=$ 2.60 ( $\mathrm{SE}=0.68)$ yr respectively. Among the $34 \mathrm{GOM}$ humpback whales depicted (Fig. 6), 8 of these samples were obtained from 4 individual whales that were biopsy sampled once each on two different occasions and ranged in time intervals from $1 \mathrm{~d}-\sim 3.3 \mathrm{yr}$. The identity of these 4 animals and their sample collection dates are provided in Table 1. Of these whales, 2 were EKA whales that were biopsy sampled at intervals approaching that of the uncertainty associated with this particular model; the 2 animals representing these time-displaced repeat sampling events are also depicted in Fig. 6.

The FA-age model shown in Fig. 6 for the Gulf of Maine population was reconstructed in Fig. 7, but in

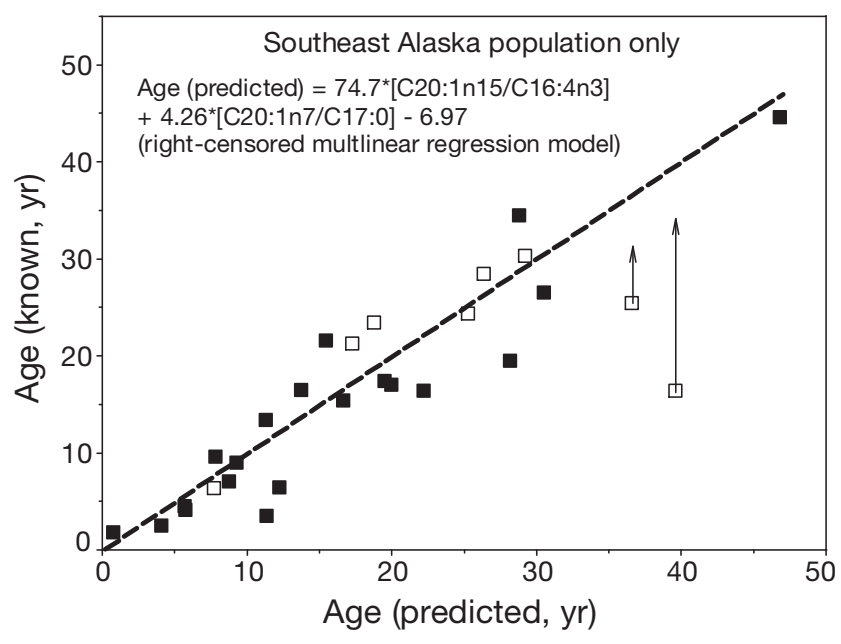

Fig. 5. Megaptera novaeangliae. Linear relationship between the known-ages (EKA and MKA) for the 28 non-excluded Southeast Alaska (SEAK) humpback whales and the ages predicted from their outer blubber fatty acid (FA) compositions using Eq. (3). The FA-age model (Eq. 3) was derived using FA-HW(age) data from both EKA and MKA whales and employing the Tobit right-censored multilinear regression procedure described in 'Materials and methods'. The dashed line represents the point in the plot where Age(predicted) equals Age(known). Symbols: EKA (closed, $\mathrm{n}=20$ ); MKA (open, $\mathrm{n}=8$ ); MKA whales predicted by the model to be much older than their minimum values are also depicted (open symbols with vertical arrows, $n=2$ ). Model uncertainties were:

$$
\sigma_{\text {Tobit }}=4.52 \mathrm{yr} ; \sigma_{\mathrm{BS}}=4.24 \mathrm{yr}
$$




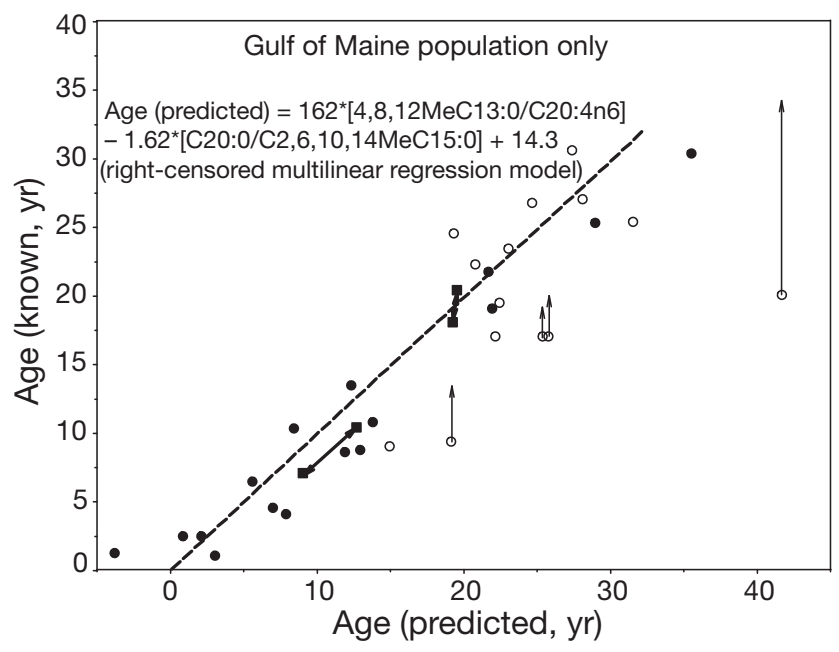

Fig. 6. Megaptera novaeangliae. Linear relationship between the known-ages (EKA and MKA) for the 34 non-excluded Gulf of Maine (GOM) humpback whales and the ages predicted from their outer blubber fatty acid (FA) compositions using Eq. (4). The FA-age model (Eq. 4) was derived using the FA-HW(age) data from both EKA and MKA whales and employed the Tobit right-censored multilinear regression procedure described in 'Materials and methods'. The dashed line represents the point in the plot where Age(predicted) equals Age (known). Symbols: EKA (closed, $\mathrm{n}=20$ ); MKA (open, $\mathrm{n}=14$ ); 2 EKA whales repeat biopsy sampled at $>2 \mathrm{yr}$ intervals (closed squares); MKA whales predicted by the model to be much older than their minimum values are also depicted (open symbols with vertical arrows, $\mathrm{n}=4$ ). Model uncertainties were: $\sigma_{\text {Tobit }}=3.25 \mathrm{yr}_{;} \sigma_{\mathrm{BS}}=2.60 \mathrm{yr}$

this plot each individual whale is coded with marker symbols that instead denote the observed preferential prey of each sub-population of whales within the Gulf while feeding, and also denote non-feeding whales that were biopsy sampled in their mating grounds during winter in the West Indies. By grouping the individual whales in this fashion, it is possible to make an initial qualitative assessment of the extent that differing diets and feeding status are likely to have on the efficacy of these FA-age models.

\section{DISCUSSION}

The current study represents the first attempt to determine whether the numerical age of humpback whales can be estimated from measurements of either individual fatty acids, FA ratios, or some linear combination thereof in their outer-blubber layers. A similar study conducted in 2007 for eastern North Pacific killer whales Orcinus orca found an empirical model based on the linear combination of 2 fatty acid ratios correlated sufficiently well with known age to enable the

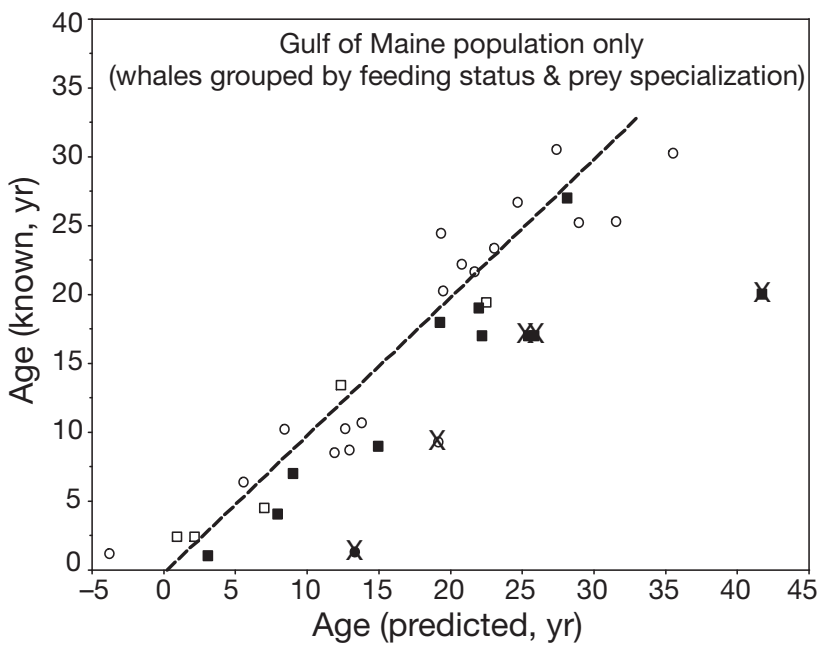

Fig. 7. Megaptera novaeangliae. Same FA-age model plot as in Fig. 6 but the points representing the individual Gulf of Maine (GOM) humpback whales are denoted by their presumed location-dependent prey preferences and feeding status. Marker symbols: presumed sandlance feeders (open circles); presumed herring feeders (open squares); unknown prey specialization (closed circles); non-feeders in the West Indies (closed squares); MKA whales predicted by the model to be much older than their minimum values (crosses, $\mathrm{n}=5$ )

ages of unknown-age killer whales to be estimated with good precision; $\sigma= \pm 3.8 \mathrm{yr}$ (Herman et al. 2008). In the current study, outer-blubber tissue samples of 70 known-age humpback whales from 2 distinct populations were collected (from the western North Atlantic, and eastern and central North Pacific oceans; Table 1, Fig. 1), and analyzed for their FA compositions. The initial results of this study provide a first indication of the potential to age humpback whales from measurements of FAs in their outer-blubber layers. Among the large number of humpback whale biopsy samples collected from these 2 regions in the last decade, the subset of samples analyzed for the current study (Table 1) were specifically chosen to represent the broadest possible range of known ages, include approximately equal numbers of each sex, and include sub-groups of whales observed to have very different diets. Samples from additional known-age whales will be analyzed in the future in order to further validate and refine the FA-age models.

To be useful as a tool for ageing humpback whales of unknown age, the empirical models derived from known-age animals must necessarily be independent of diet, so that small future changes in specific diet will not adversely affect the age estimates. Humpback whales are generalists, feeding on a variety of small schooling forage fish species and euphausiids across their range. Dietary preferences in the Gulf of Maine 
have been inferred, and are primarily based on observations of prey during surface feeding as well as the spatial distribution of prey species. Sandlance Ammodytes spp. is generally thought to be the preferred prey species in the southwestern Gulf of Maine (Overholtz \& Nicolas 1979, Payne et al. 1986, 1990). Whereas Atlantic herring Clupea harengus can be found throughout the entire GOM area, it is thought to be the main piscine prey only in the northern areas (Hain et al. 1982, Paquet et al. 1997, Weinrich et al. 1997). Euphausiids (Paquet et al. 1997) and mackerel (Mitchell 1973, Geraci et al. 1989) are also documented prey species in the Gulf of Maine, but their relative importance to the diet of GOM humpbacks is unknown. Finally, Laerm et al. (1997) reported the stomach contents of one spring Gulf of Maine whale stranding to include Atlantic croaker Micro-pogonias undulatus, spot Leiostomus xanthurus and weakfish Cynoscion regalis. However, they also found these coastal fish species in humpback whales stranded off the coast of the mid-Atlantic USA in winter, outside the typical summer feeding range of this population.

In contrast, the primary prey items of the Southeast Alaska humpback whales are less well-known but are believed to comprise a mix of euphausiids, Pacific herring Clupea pallasii, sandlance Ammodytes spp., capelin Mallotus villosus, and juvenile walleye pollock Theragra chalcogramma. Other prey species (e.g. other smelts and small schooling fishes) have been observed to be taken by SEAK whales, but are believed to be minor contributors to their total diet.

Although the focus of this study was not to use blubber fatty acid results to infer the primary prey of the 2 populations of humpback whales described here, it is instructive to assess how the outer-blubber fatty acid compositions of the whales from these 2 populations seem to differ. The multidimensional scaling plots shown (Fig. 2) demonstrate that the outer-blubber FA compositions of the GOM population of humpback whales are very different to those of the SEAK population, both in terms of their total FA compositions, and with respect to those FAs believed to originate primarily from diet. The importance of this perceived difference in diet between GOM and SEAK populations is that 2 independent FA-age models (one based only on EKA animals, and the second based on both EKA and MKA animals combined) were found that adequately described the relationship between specific fatty acid ratios and known age simultaneously for both populations, despite clear differences in diet.

During the development of the FA-age models, animals having high phospholipid compositions concurrent with low PUFAs were observed to strongly deviate from all other samples (including those of comparable age) with respect to the functional dependences of their individual FAs (and FA ratios) with known age; it became apparent that these samples should be rejected as 'outliers' and not be included as data points in modeling processes. In combination multidimensional scaling analysis (Fig. 2) and TLC-FID analyses of the outer-blubber FA compositions of these whales helped identify individual whales that had abnormal fatty acid and/or lipid class compositions (relative to all other members of their respective populations). Thus, both MDS analyses of blubber FAs along with lipid class analyses of humpback whale blubber tissues are an integral first step in the development of FA-age models. These methods should also be used as prescreening tools to fully characterize the blubber chemistry of unknown-age humpback whales such that age predictions based on FA-age models for any unknownage whale that exhibits abnormal lipid and/or FA profile should be flagged as uncertain.

Although several individual fatty acids present in the outer blubber layers of the GOM and SEAK humpback whales exhibited a moderate correlation with age when these populations were viewed independently (Table 2), none were well correlated with both populations simultaneously. Many of the differences observed between these 2 populations may be attributable to the very different presumptive diets of these 2 populations. Regardless of the cause(s) responsible for these differences, it was clear from the onset that it would not be possible to accurately predict the age of unknown-age humpback whales using any one individual FA.

It should also be noted that the classes of FAs that were most correlated with humpback whale age were long-chain monounsaturated (LCMU) and multi-methyl branched-chain FAs, both of which are relatively ubiquitous in the marine environment. This finding is in stark contrast to the results described by Herman et al. (2008) for eastern North Pacific killer whales Orcinus orca, wherein it was the shorter-chain monounsaturated and iso- and anteiso-branched chain FAs (in particular anteiso-C15:0) that correlated best with age for this cetacean. Conversely, in the current study anteisoC15:0 was observed to be among the most highly noncorrelated individual FA measured in these 2 populations of humpback whales (Table 2). Based on the findings of both studies, it appears likely that no single model will be found that is capable of estimating age through blubber FA compositions for all cetaceans; rather, relationships between whale age and FA composition (if/when they are found to exist at all) will be species-specific.

In the current study, specific ratios of fatty acids present in the outer blubber of whales from the Gulf of Maine, Southeast Alaska, and both populations combined were used to derive bi-variate FA-age relation- 
ships that were highly correlated with age, and also largely independent of diet and sex. For example, the FA-age model derived for exact-aged humpback whales from both populations (Fig. 3; upper panel) exhibited a clear relationship between the $2 \mathrm{FA}$ ratios (C20:1n15/C17:1n8 \& C14:1n5/C15:0) and EKA. The efficacy of the exact-aged model (Eq. 1) was further validated by using this model to predict the ages of the minimum-aged whales from both populations and comparing these model-predicted ages to their MKAs (Fig. 3; lower panel). In support of the assertion that both this particular exact-aged model, as well as the model derived from both the EKA and the MKA FAage data for these 2 combined populations (Fig. 4; Eq. 2), are both largely independent of diet is the observation that the FA ratio-age data for both the GOM and SEAK populations generally fall along the same regression lines. As noted above, MDS analyses of the FA compositions of these 2 populations (Fig. 2) demonstrate that they have very different diets. Moreover, both of these models (Eqs. 1 \& 2) appeared to be independent of sex (due to the fact that animals of both sexes were also equally scattered about the predicted FA-age lines).

Between the 2 models represented by Eqs. (1) \& (2), the latter is probably the most robust, owing to the fact that Eq. (2) was derived from a substantially larger number of known-age data points, and perhaps more importantly, it also allowed for the inclusion of many more adult-aged whales (greater than $\sim 20 \mathrm{yr}$ in age) into the modeling process. For this same reason, the uncertainty estimate $\left(\sigma_{\text {Tobit }}=5.25 \mathrm{yr}\right)$ derived from the right-censored MKA and EKA model (Fig. 4; Eq. 2) is expected to be the best, most conservative predictor of how these FA-age models will perform when applied to unknown-aged whales in the future. Thus, from this limited dataset, it appears that it is possible to predict with $>95 \%$ confidence $( \pm 2 \sigma)$ the age of any one individual humpback whale from either of these 2 regions with a precision of slightly greater than $10 \mathrm{yr}$. Although this precision may not be entirely adequate for the purpose of detailed population modeling, age uncertainties of this magnitude are sufficient to enable broad age categorizations within these populations. At present, the efficacy of this model for humpback whales outside these specific areas (GOM and SEAK) is not known and will require additional testing.

FA-age models were also derived for each population of humpback whales separately to determine if the level of uncertainty in the ages predicted using outerblubber fatty acid compositional results could be further reduced. The results presented in Fig. 5 demonstrate that the FA-age model derived specifically for the SEAK population was more precise $\left(\sigma_{\text {Tobit }}=4.52 \mathrm{yr}\right)$ as compared to the uncertainty obtained for the 2- population model represented by Eq. (2) $\left(\sigma_{\text {Tobit }}=\right.$ 5.25 yr). Similarly, the optimum FA-age model derived for the GOM population alone (Fig. 6; Eq. 4) also resulted in a bi-variate FA-age relationship in which the estimated uncertainty $\left(\sigma_{\text {Tobit }}=3.25 \mathrm{yr}\right)$ was less than that of the combined 2-population model represented by Eq. (2). These combined results suggest that ageing humpback whales following the approach described here (when possible) will likely become more precise when empirical models are derived for the specific populations to be studied.

It is also instructive to note that the 2 individual GOM humpback whales that were biopsy sampled twice (Sample nos. 13/19 and 25/29; Table 1; Fig. 6) and more than $2 \mathrm{yr}$ apart had predicted ages that increased with time; the increases in predicted ages were in reasonable agreement with the known amount of time that elapsed between sampling events. This finding provided some small additional evidence that the GOM FA-age model represented by Eq. 4 is valid for this particular population of whales.

Among the 4 models derived (Eqs. 1-4), it is anticipated that it is the combined 2-population model (i.e. Eq. 2) that is most likely to be applicable to populations beyond the specific humpback populations studied here. Extension to populations beyond these 2 specific areas will clearly require additional validation by (1) acquiring blubber samples from a sufficient number of known-age humpback whales that span a full range of ages within the new areas (e.g. from whales having their ages determined from long-term photo-ID studies), and then (2) showing their model-predicted ages to be in good agreement with their known ages. Once a new FA-age model is derived and adequately validated, expensive and difficult to maintain photo-ID studies could be either curtailed, or terminated completely.

Additional insight into the extent that the FA-age models described above are independent of diet and feeding status was provided by re-plotting in Fig. 7 the FA-age model specific to the Gulf of Maine population (Fig. 6); but now where the individual whales were grouped instead by their known prey preferences and feeding status. In this modified plot, humpback whales believed to specialize on sandlance in the southwestern Gulf of Maine (GOM-SW; $\mathrm{n}=17$ ) can more readily be compared against whales thought to specialize on herring from the northern Gulf of Maine $\left(\mathrm{GOM}-\mathrm{N}_{;} \mathrm{n}=\right.$ 5); In short, GOM-SW whales were observed to fall along (and were equally scattered about) the same predicted FA-age line as the GOM-N whales. Although the number of known-age whales with a herring specialization was admittedly small by comparison to presumed sandlance-feeders, this observation again demonstrates that FA-age models based on ratios of 
individual FAs can be derived that are suitably independent of specific diets. A comparable analysis of the extent that variable diets affect the SEAK only population (Fig. 5) is not possible, because the prey specializations of the individual SEAK whales and/or groupings of whales are not well characterized at present (unlike individual GOM population whales that could be identified with a specific foraging group, hence their specific prey).

Similarly, the FA-age results obtained for the subset of GOM population whales that were biopsy sampled in winter (i.e. whilst on their mating grounds in the West Indies, and therefore not feeding for an extended period) were compared to the remaining subset of whales biopsied while feeding in spring, summer and fall in the Gulf of Maine (Fig. 7). Owing to the fact that the predicted ages for the feeding and non-feeding whales essentially fell along the same general regression line, these limited results illustrate that feeding status will likely have only a minimal effect on the accuracy of this particular model (Eq. 4), and perhaps (by inference) to all 4 multilinear FA-age models derived in this study. Admittedly, the non-feeding group of whales appeared to have predicted ages that were shifted to slightly higher values by $\sim 2$ to 3 yr relative to the feeding group of whales, but this offset was within the uncertainty of the model. It is not known from these limited data if this slight offset was statistically significant.

The data presented in Fig. 7 further suggest that age predictions based on blubber fatty acid ratios may be more precise if the blubber biopsy samples are collected during nonfeeding periods. This hypothesis is based on the observation that, although the knownage versus predicted age results for non-feeding whales were somewhat offset in their predicted ages relative to feeding whales, they appear to be less scattered (more linear) than those of their feeding counterparts. This observation indicates that although differences in specific diets among individual feeding whales may exert a small (yet discernable) influence on the outer-blubber FA compositions of the specific fatty acids modeled here, the potential adverse influence of differing diets among individual whales is likely to be at a minimum during periods of fasting.

Based on these preliminary findings, it is concluded that it should be possible to estimate the numerical age of unknown-age humpback whales following the general approach described here. However, it is cautioned that these FA-age models are entirely empirical in nature, and a clear understanding of the underlying mechanisms responsible for the time-dependent changes in the specific fatty acid ratios that seemingly drive these relationships is presently lacking. Moreover, it is fully acknowledged that the inclusion of
MKA FA-age data into these models (Eqs. 2 to 4) adds an additional level of uncertainty into these relationships; but for the present study it was deemed advantageous to include the FA-age data for these MKA whales in order to substantially increase the total number of whales modeled (in particular, the inclusion of whales older than $20 \mathrm{yr}$ of age). In the future, when blubber samples from older EKA animals become available and can be analyzed for outer-blubber fatty acid compositions, the data points corresponding to these older MKA whales can be replaced by data from EKA whales and these models updated. Replacement of MKA data by EKA data will not only provide greater confidence in these models, but also provide significantly improved estimates of their underlying uncertainties. In each of the $3 \mathrm{FA}$-age regression models (Eqs. 2 to 4 ) described above, $\sigma_{\text {Tobit }}$ estimates of uncertainty were larger that the bootstrap-derived estimates $\left(\sigma_{\mathrm{BS}}\right)$ in which the MKA animals were excluded. Thus, for the moment, the larger $\sigma_{\text {Tobit }}$ values are adopted as the most conservative (best) estimate of the uncertainties of these models

While it is tempting to infer the life span of humpback whales from these results, the current study was not designed to investigate this question: a different sampling strategy would be required to reliably detect the oldest whales in the study populations, and further work would be necessary to derive new FA relationships for whales having ages significantly older than those examined here. Thus, it is advised against interpreting these results in the context of life span, although these techniques are considered a promising method for further investigation.

Finally, it is cautioned that each of the 4 FA-age models (Eqs. 1 to 4 ) will be valid only when the procedures and analytical methods used to measure the individual FAs that go into defining these bi-variate models are equivalent to those used in our laboratory. Therefore it is strongly advised that (whenever possible) each laboratory electing to apply the FA-ageing method outlined in this study should derive their own set of empirical FA-age relationships from knownaged animals. This should reduce the potential for unexpected biases in analytical results that may occur among laboratories employing differing analytical methods. Thereafter, the explicit empirical models derived by each individual laboratory can be used to predict the age of any unknown-aged whale of interest.

Acknowledgements. We greatly appreciate the technical assistance of D. Burrows, D. Boyd and J. Bolton of the Northwest Fisheries Science Center (NWFSC) in map creation, sample processing and QC data management procedures, respectively. Thanks also to B. Reichert and K. Peck of NWFSC for their careful review of this manuscript. We also 
thank the following individuals for their assistance in securing data used in this study: D. Mattila, L. Baraff, C. Carlson, C. Elfes, A. Kennedy, P. Kamath, J. Jarzobski, S. Landry and E. Lyman who contributed to field and cataloguing efforts in the GOM; P. Palsbøll and M. Bérubé who conducted molecular genetic sexing of GOM samples; F. Wenzel and R. Pace for providing access to Northeast Fisheries Science Center West Indies samples from the MONAH project; S. Lewis, H. Riley, and J. Neilson for collecting biopsy samples in SEAK; F. Gulland for expert assistance in the necropsies of GBNP-Mn2001 and GBNP-MnA-2004; A. Jensen and E. Lyman of NOAA for blubber sample collection of Mn-071307; C. Lockyer and $\mathrm{H}$. Kato for performing the ear plug GLG counts for GBNP-Mn-2001 and J. Neilson and J. Cedarleaf for maintaining accurate sighting histories of whales in the SEAK catalog. We are grateful for the funding support of T.K. Rowles from the Marine Mammal Health and Stranding Response Program of NOAA Fisheries; and to the North Pacific basin wide study of humpback whales SPLASH (Structure of Populations, Levels of Abundance and Status of Humpbacks) for funding for data collected in 2004 and 2005 in SEAK. Humpback whale research was conducted under one of the following tissue sample and/or data collection permits: NMFS Permit \#932-1489-07; NMFS Permit \#633-1483; the authorization of the Department of Fisheries and Oceans, Canada. SEAK data were collected under numerous NMFS Scientific Research Permits issued to J. Straley and Glacier Bay National Park and Preserve from 1979 to present.

\section{LITERATURE CITED}

Bannister J, Best P, Brownell R, Clapham PJ, Kato H (2000) Calibration of humpback whale earplug readings. J Cetacean Res Manag 2(Suppl.):194

Baraff LS, Weinrich MT (1993) Separation of humpback whale mothers and calves on a feeding ground in early autumn. Mar Mamm Sci 9:431-434

Baraff LS, Clapham PJ, Matilla DK, Bowman RS (1991) Feeding behavior of a humpback whale in low-latitude waters. Mar Mamm Sci 7:197-202

Barrett-Lennard LG, Smith TG, Ellis GE (1996) A cetacean biopsy method using lightweight pneumatic darts, and its effect on the behavior of killer whales. Mar Mamm Sci 12: $14-27$

Best PB (2010) A note on the age at sexual maturity of humpback whales. J Cetacean Res Manage, Special Issue 3 (in press)

Brown MW, Kraus SD, Gaskin DE (1991) Reaction of North Atlantic right whales (Eubalaena glacialis) to skin biopsy sampling for genetic and pollutant analysis. Rep Int Whaling Comm 13(special issue):81-89

Chittleborough RG (1959) Determination of age in the humpback whale, Megaptera nodosa (Bonnaterre). Aust J Mar Freshwater Res 10:125-143

Clapham PJ, Mattila DK (1993) Reactions of humpback whales to skin biopsy sampling on a West Indies breeding ground. Mar Mamm Sci 9:382-391

Clapham PJ, Mayo CA (1987) Reproduction and recruitment of individually identified humpback whales, Megaptera novaeangliae, observed in Massachusetts Bay, 1979-1985. Can J Zool 65:2853-2863

Dawbin WH (1966) The seasonal migratory cycle of humpback whales. In: Norris KS (ed) Whales, dolphins and porpoises. University of California Press, Berkeley, p 145-170

$>$ Dennis C (2006) A gentle way to age. Nature 442:507-508

Ferrero RC, Walker WA (1999) Age, growth, and reproductive patterns of Dall's porpoise (Phocoenoides dalli) in the central North Pacific Ocean. Mar Mamm Sci 15:273-313

Gauthier J, Sears R (1999) Behavioral response of four species of balaenopterid whales to biopsy sampling. Mar Mamm Sci 15:85-101

George JC, Bada J, Zeh J, Scott L, Brown SE, O'Hara T, Suydam R (1999) Age and growth estimates of bowhead whales (Belaena mysticetus) via aspartic acid racemization. Can J Zool 77:571-580

Geraci JR, Anderson DM, Timperi RJ, St. Aubin DJ, Early GA, Prescott JH, Mayo CA (1989) Humpback whales Megaptera novaeangliae fatally poisoned by dinoflagellate toxin. Can J Fish Aquat Sci 46:1895-1898

Hain JH, Carter GR, Kraus SD, Mayo CA, Winn HE (1982) Feeding behaviour of the humpback whale, Megaptera novaeangliae, in the western North Atlantic. Fish Bull 80: 259-268

Hammond PS, Mizroch SA, Donovan GP (1990) Individual recognition of cetaceans: use of photo-identification and other techniques to estimate population parameters. Reports Int Whaling Comm (special issue) 12:440

> Herman DP, Burrows DG, Wade PR, Durban JW and others (2005) Feeding ecology of eastern North Pacific killer whales from fatty acid, stable isotope, and organochlorine analyses of blubber biopsies. Mar Ecol Prog Ser 302: 275-291

> Herman DP, Matkin CO, Ylitalo GM, Durban JW and others (2008) Assessing age-distributions of killer whale (Orcinus orca) populations from the composition of endogenous fatty acids in their outer-blubber layers. Mar Ecol Prog Ser 372:289-302

> Hohn AA, Fernandez S (1999) Biases in dolphin age structure due to age estimation technique. Mar Mamm Sci 15: $1124-1132$

Hohn AA, Scott MD, Wells RS, Sweeney JC, Irvine AB (1989) Growth layers in teeth from known-age, free-ranging bottlenose dolphin. Mar Mamm Sci 5:315-342

Ichihara T (1966) Criterion for determining age of fin whale with reference to ear plug and baleen plate. Scientific Reports Whales Res Institute Tokyo 20:17-82

> Iverson SJ, Field C, Bowen WD, Blanchard W (2004) Quantitative fatty acid signature analysis: a new method of estimating predator diets. Ecol Monogr 74:211-235

Katona S, Baxter P, Brazier O, Kraus S, Perkins J, Whitehead $\mathrm{H}$ (1979) Identification of humpback whales by fluke photographs. In: Winn HE, Olla BL (eds) Behavior of Marine Animals, Vol. 3. Plenum Press, New York, NY, p 33-44

> Koopman HN, Iverson SJ, Gaskin DE (1996) Stratification and age-related differences in blubber fatty acids of the male harbour porpoise (Phocoena phocoena). J Comp Physiol [B] 165:628-639

> Koopman HN, Iverson SJ, Read AJ (2003) High concentrations of isovaleric acid in the fats of odontocetes; variation and patterns of accumulation in blubber vs. stability in the melon. J Comp Physiol [B] 173:247-261

Krahn MM, Ylitalo GM, Burrows DG, Calambokidis J and others (2001) Organochlorine contaminant concentrations and lipid profiles in eastern North Pacific gray whales (Eschrichtius robustus). J Cetacean Res Manag 3: $19-29$

Krahn MM, Herman DP, Ylitalo GM, Sloan CA, and others (2004) Stratification of lipids, fatty acids and organochlorine contaminants in blubber of white whales and killer whales. J Cetacean Res Manag 6:175:189

Laerm J, Wenzel F, Craddock JE, Weinland D and others (1997) New prey species for northwestern Atlantic humpback whales. Mar Mamm Sci 13:705-711 
Lambertsen RH (1987) A biopsy system for large whales and its use for cytogenetics. J Mammal 68:443-445

Lockyer C (1972) The age at sexual maturity of the southern fin whale (Balaenoptera physalus) using annual layer counts in the ear plug. ICES J Mar Sci 34:276-294

Lockyer C (1984) Age determination by means of the earplug in baleen whales. Rep Int Whaling Comm 34:692-696

Mitchell E (1973) Draft report on humpback whales taken under special scientific permit by eastern Canadian land stations, 1969-1971. Rep Int Whaling Comm 23:138-154

Møller P (1999) Distinguishing between foraging patterns and sexual maturity of harbour porpoise (Phocoena phocoena) utlilising blubber fatty acid signature and classification regression analysis. MSc thesis, Århus University

Olsen E, Sunde J (2002) Age determination of minke whales (Balaenoptera acutorostrata) using the aspartic acid racemization technique. Sarsia 87:1-8

Overholtz WJ, Nicolas JR (1979) Apparent feeding by the fin whale, Balaenoptera physalus, and the humpback whale, Megaptera novaeangliae, on the American sandlance, Ammodytes americanus, in the northwest Atlantic. Fish Bull 77:285-287

Palsbøll PJ, Larsen F, Sigurd-Hansen E (1991) Samping of skin biopsies from free-ranging large cetaceans in West Greenland: development of new biopsy tips and bolt designs. Rep Int Whaling Comm 13(special issue):71-79

Paquet D, Haycock C, Whitehead W (1997) Numbers and seasonal occurrence of humpback whales, Megaptera novaeangliae, off Brier Island, Nova Scotia. Can Field Nat 111:548-552

Payne PM, Nicolas JR, O'Brien L, Powers KD (1986) The distribution of the humpback whales Megaptera novaeangliae on Georges Bank and in the Gulf of Maine in relation

Editorial responsibility: John Piatt, Anchorage, Alaska, USA to densities of the sand eel Ammodytes americanus. Fish Bull 84:271-277

Payne PM, Wiley DN, Young SB, Pittman S, Clapham PJ, Jossi JW (1990) Recent fluctuations in the abundance of baleen whales in the southern Gulf of Maine in relation to changes in selective prey. Fish Bull 88:687-696

Sloan CA, Brown DW, Ylitalo GM, Buzitis J and others (2006) Quality assurance plan for analyses of environmental samples for polycyclic aromatic compounds, persistent organic pollutants, fatty acids, stable isotope ratios, lipid classes, and metabolites of polycyclic aromatic compounds. U.S. Dept. of Commerce, NOAA Tech Memo, NMFSNWFSC-77, p 30

Straley JM, Quinn TJ II, Gabriele CM (2009) Assessment of mark recapture models to estimate the abundance of a humpback whale feeding aggregation in Southeast Alaska. J Biogeogr 36:427-438

Weinrich MT, Lambertsen RH, Belt CR, Schilling MR, Iken HJ, Syrjala SE (1992) Behavioral reactions of humpback whales Megaptera novaeangliae to biopsy procedures. Fish Bull 90:588-598

Weinrich MT, Martin M, Griffiths R, Bove J, Schilling M (1997) A shift in distribution of humpback whales, Megaptera novaeangliae, in response to prey in the southern Gulf of Maine. Fish Bull 95:826-836

Winn HE, Bischoff WL, Taruski AG (1973) Cytological sexing of Cetacea. Mar Biol 23:343-346

Ylitalo GM, Yanagida GK, Hufnagle L, Krahn MM (2005) Determination of lipid classes and lipid content in tissues of aquatic organisms using a thin layer chromatography/ flame ionization detection (TLC/FID) microlipid method. In: Ostrander GK (ed) Techniques in Aquatic Toxicology, Volume 2. CRC Press, Boca Raton, FL, p 227-237

Submitted: March 12, 2009; Accepted: July 27, 2009

Proofs received from author(s): October 6, 2009 